\title{
Desenvolvimento vegetativo e acúmulo de massa seca com a adubação de porta-enxertos cítricos cultivados em tubetes
}

\author{
Vegetative growth and dry matter accumulation with fertilization of citrus rootstocks \\ grown in container
}

\author{
Paulo de Tarso Lima Teixeira ${ }^{\mathrm{I}}$ Gilmar Schäfer ${ }^{\mathrm{I}}$ Paulo Vitor Dutra de Souza ${ }^{\mathrm{I}^{*}}$ Abel Todeschini $^{\mathrm{I}}$
}

\section{- NOTA -}

\section{RESUMO}

\begin{abstract}
Com o objetivo de avaliar o efeito de diferentes substratos e doses de solução nutritiva na formação dos portaenxertos Poncirus trifoliata, citrangeiro 'Troyer', citrumeleiro 'Swingle' e tangerineira 'Sunki' em tubetes, realizou-se, sob condições de casa de vegetação, um experimento com delineamento experimental em blocos casualizados, em esquema de parcelas subdivididas com três repetições e cada subparcela constituida por 20 tubetes. Na parcela principal, foram testadas quatro doses de solução nutritiva $(0 ; 0,25 ; 0,5$ e 1,0g $L^{-1}$ de adubo - relação $N=1 ; P=0,14 ; K=0,34 ; C a=1,41$; e $M g=0,13$, sendo a concentração de $N$ na solução estoque de $7,2 \%$ aplicada via água de irrigação, em fertirrigação contínua, com sistema de irrigação por subirrigação. Nas subparcelas, foram testados quatro porta-enxertos cítricos e dois substratos comerciais. A solução nutritiva foi trocada a cada 15 dias. O máximo crescimento e acúmulo de massa seca foram, de um modo geral, alcançados na aplicação da dose máxima de solução nutritiva, com exceção da área foliar do 'Trifoliata' e massa seca da parte aérea da tangerineira 'Sunki'. O substrato comercial 1 propiciou o maior crescimento e acúmulo de biomassa, independente dos portaenxertos e das doses de fertilizante utilizados.
\end{abstract}

Palavras-chave: Citrus spp, propagação, desenvolvimento vegetativo, adubação, ambiente protegido.

\begin{abstract}
An experiment was carried out in the greenhouse aiming to evaluate the effect of different substrates and levels of nutrient solution in the formation of Poncirus trifoliata, 'Troyer' Citrange, 'Swingle' Citrumelo and tangerine 'Sunki' citric rootstock grown in containers. The experimental design was a randomized blocks in split plot scheme with three replications. Each sub-plot had twenty containers. The main plots received four levels of nutrient solution $\left(0 ; 0.25 ; 0.5 ; 1.0 \mathrm{~g} \mathrm{~L}^{-1}\right.$ relationship $N=1 ; P=0,14 ; K=0,34 ; C a=1,41 ; M g=0,13$ and $N$ concentration in the stock solution of $7.2 \%$ ) applied by water irrigation in a continuous fertilization system in a floating irrigation system. The sub-plots tested four citric rootstocks and two commercial substrates. The nutritive solution was changed at 15-day intervals. The maximum growth and dry mass accumulation, in general, reached with the application of the maximum level of nutritive solution, except the foliar area of 'Trifoliata and dry mass of the aerial part of tangerine 'Sunki'. The commercial substrate 1 provided the greater growth and biomass accumulation, independently of stock for grafting and dosages of fertilizers used.
\end{abstract}

Key words: Citrus spp., propagation, vegetative growth, fertilization, protected environment.

'Departamento de Horticultura e Silvicultura, Faculdade de Agronomia, Universidade Federal do Rio Grande do Sul, Av. Bento Gonçalves, 7712, Bairro Agronomia, CP 15100, 91501-970, Porto Alegre, RS, Brasil. E-mail: pvdsouza@ufrgs.br. *Autor para correspondência. 
Há carência de informações nas pesquisas disponíveis sobre adubação em sistemas de produção de mudas envasadas. Há muitas questões e dúvidas a respeito dos métodos de adubação, demanda nutricional específica para cada tipo de porta-enxerto empregado, diagnóstico de desordens nutricionais, interpretação de resultados de análise química de substratos e manejo quanto ao método de irrigação, que sejam capazes de responder e orientar o melhor manejo nutricional e consequente melhor aproveitamento dos nutrientes aplicados.

O presente estudo teve como objetivo avaliar o efeito de doses de uma solução de macronutrientes, aplicados via água de irrigação, e de diferentes substratos sobre o crescimento e a produção de massa seca de porta-enxertos cítricos, produzidos em ambiente protegido.

O experimento foi executado no período de junho a dezembro de 2006 em casa de vegetação da Estação Experimental Agronômica da Universidade Federal do Rio Grande do Sul (EEA/ UFRGS), situada na Rodovia BR 290 (Km 146), em Eldorado do Sul, RS.

A semeadura foi realizada em tubetes cônicos de polietileno preto (volume de $120 \mathrm{~cm}^{3}$ ), vazados na parte basal, fixados em bancadas metálicas a um metro da superfície. $O$ delineamento experimental adotado foi o de blocos casualizados, em esquema de parcelas subdivididas com três repetições, cada subparcela constituída por 20 tubetes. Na parcela principal, foram testadas quatro doses de solução nutritiva $\left(0 ; 0,25 ; 0,5 ; \mathrm{e} 1,0 \mathrm{~g} \mathrm{~L}^{-1}\right.$ de adubo), aplicada via água de irrigação, em sistema de fertirrigação contínua. Nas subparcelas, foram testados quatro porta-enxertos cítricos: 'Trifoliata' (Poncirus trifoliata [L.] Raf.); o citrangeiro 'Troyer' (P. trifoliata [L.] Raf. x Citrus sinensis [L.] Osbeck.); a tangerineira 'Sunki' (C. sunki hort. ex Tan.); e o citrumeleiro 'Swingle' (P. trifoliata [L.] Raf. x C. paradisi Macf.). Também foram avaliados dois substratos: o substrato Plantmax Hortaliças HT Comercial 1 - (fabricante Eucatex $x^{\hat{a}}$ e o substrato Turfa Fértil ${ }^{\circledR}$ FG6 - Comercial 2. As irrigações foram feitas mediante um sistema de subirrigação por capilaridade (SCHÄFER, 2004).

A relação de nutrientes adicionados na água de irrigação, considerando o valor de $\mathrm{N}$ como sendo 1 foi de: $\mathrm{P}=0,14 ; \mathrm{K}=0,34 ; \mathrm{Ca}=1,41 ; \mathrm{e} \mathrm{Mg}=0,13$, sendo a concentração de $\mathrm{N}$ na solução estoque de $7,2 \%$. Os fertilizantes empregados eram totalmente solúveis e utilizados para fertirrigação. A solução nutritiva foi adicionada à água de irrigação quando, ao menos, $10 \%$ das plântulas de cada cultivar emergiram. A solução nutritiva foi totalmente trocada a cada 15 dias para diminuir efeitos de desbalanços nutricionais.

Foram determinados, aos 180 dias após a semeadura (DAS), o comprimento da parte aérea, o diâmetro da haste no nível do colo; a área foliar por plântula e a massa seca da raiz e da parte aérea. As médias foram submetidas à análise de variância e comparadas pelo teste de Duncan, a $5 \%$ de probabilidade de erro. As variáveis estudadas para os porta-enxertos cítricos em função das diferentes doses de solução nutritiva foram submetidas à análise de regressão polinomial.

Não houve interação entre os fatores portaenxerto e substratos e doses de fertilizantes e substratos. O desenvolvimento vegetativo dos portaenxertos mostrou-se significativamente diferente, independentemente dos substratos e das doses de fertilizantes (Tabela 1).

Aos 180 dias após a semeadura, os portaenxertos 'Trifoliata' e citrumeleiro 'Swingle' atingiram

Tabela 1 - Altura da parte aérea (A), Diâmetro no nível do colo (D), Número de Folhas por Planta (NFP), Área Foliar por Planta (AFP), Massa Seca de Raiz (MSR) e Massa Seca da Parte Aérea (MSPA) aos 180 dias após a semeadura, médias, de dois substratos e de quatro porta-enxertos cítricos e quatro doses de solução nutritiva via água de irrigação. EEA/UFRGS, Eldorado do Sul, 2006.

\begin{tabular}{llllllll}
\hline \multirow{2}{*}{ Tratamento } & & A & D & & AFP & MSR & MSPA \\
& & $(\mathrm{cm})$ & $(\mathrm{mm})$ & NFP & $\left(\mathrm{cm}^{2}\right)$ & $(\mathrm{g})$ & $(\mathrm{g})$ \\
\hline \multirow{5}{*}{ Porta-enxertos } & C. 'Swingle' & $14,73 \mathrm{a}{ }^{1}$ & $3,30 \mathrm{a}$ & $11,38 \mathrm{a}$ & $36,85 \mathrm{a}$ & $0,45 \mathrm{a}$ & $0,63 \mathrm{a}$ \\
& 'Trifoliata' & $14,86 \mathrm{a}$ & $2,60 \mathrm{~b}$ & $12,16 \mathrm{a}$ & $24,10 \mathrm{~b}$ & $0,38 \mathrm{~b}$ & $0,44 \mathrm{~b}$ \\
& C. 'Troyer' & $10,31 \mathrm{~b}$ & $2,50 \mathrm{~b}$ & $8,48 \mathrm{~b}$ & $20,46 \mathrm{~b}$ & $0,23 \mathrm{c}$ & $0,31 \mathrm{c}$ \\
& T. 'Sunki' & $9,88 \mathrm{~b}$ & $2,24 \mathrm{c}$ & $12,66 \mathrm{a}$ & $34,70 \mathrm{a}$ & $0,19 \mathrm{c}$ & $0,38 \mathrm{~b}$ \\
\multirow{3}{*}{ Substratos } & CV $(\%)$ & 7,3 & 7,2 & 10,9 & 22,6 & 14,2 & 14,3 \\
& Comercial & $13,10 \mathrm{a}$ & $2,78 \mathrm{a}$ & 11,44 & 30,13 & $0,36 \mathrm{a}$ & $0,48 \mathrm{a}$ \\
& Comercial & $11,78 \mathrm{~b}$ & $2,54 \mathrm{~b}$ & 10,90 & 27,93 & $0,27 \mathrm{~b}$ & $0,40 \mathrm{~b}$ \\
& CV(\%) & 10,3 & 6,9 & 13,5 & 33,4 & 19,8 & 20,0 \\
\hline
\end{tabular}

${ }^{1}$ Médias seguidas por letras diferentes e minúsculas na coluna, diferem significativamente pelo teste de Duncan em nível de $5 \%$ de probabilidade de erro. 
alturas próximas a $15 \mathrm{~cm}$, superiores às do citrangeiro 'Troyer' e a tangerineira 'Sunki', que alcançaram alturas em torno de $10 \mathrm{~cm}$. O citrumeleiro 'Swingle' apresentou o maior diâmetro no nível do colo, seguido pelos portaenxertos 'Trifoliata' e 'Troyer' e o menor desenvolvimento em diâmetro foi apresentado pela tangerineira 'Sunki' (Tabela 1).

O número de folhas por planta foi significativamente menor no citrangeiro 'Troyer' em relação aos demais, que não diferiram entre si (Tabela 1). O citrumeleiro 'Swingle' obteve a maior área foliar por planta, não diferindo significativamente da tangerineira 'Sunki' e ambos foram superiores às outras duas cultivares de porta-enxertos para este parâmetro. O citrumeleiro 'Swingle' apresentou as maiores massas secas de raiz e da parte aérea, seguido pelo 'Trifoliata', depois pelo citrangeiro 'Troyer' e pela tangerineira 'Sunki' (Tabela 1). Esses dois últimos não apresentaram diferenças significativas entre si, exceto para massa seca da parte aérea. Também foram observadas diferenças em área foliar entre os porta-enxertos estudados e o 'Trifoliata', que teve o menor índice área foliar, apesar de apresentar o maior número de folhas, devido a características intrínsecas da própria espécie, pois é normal a esse porta-enxerto apresentar folhas pequenas, quando comparado a outros porta-enxertos cítricos.

Os resultados encontrados estão de acordo com os de outros trabalhos sobre produção de portaenxertos cítricos em ambiente protegido, no qual é comum encontrar diferenças entre os porta-enxertos para as variáveis avaliadas (SCHÄFER et al., 2000). SCHÄFER (2004) obteve, aos 120DAS, alturas superiores para o 'Trifoliata' e menores para os 'citrangeiros' FEPAGRO ‘C37' e FEPAGRO ‘C13'.

A aplicação da solução nutritiva proporcionou efeito linear crescente na altura dos portaenxertos, não diferindo entre estes (Figura 1A). Quanto ao diâmetro da haste, todos os porta-enxertos tiveram efeito linear crescente das doses de solução nutritiva (Figura 1B), sendo que o citrumeleiro 'Swingle' atingiu o maior diâmetro, o 'Trifoliata' e o 'Troyer' obtiveram diâmetros em torno dos 3,0mm, enquanto a tangerineira 'Sunki' teve o menor diâmetro.

Quanto ao número de folhas por planta, o citrumeleiro 'Swingle' mostrou efeito quadrático negativo, saturando a resposta na dose de $0,5 \mathrm{~g} \mathrm{~L}^{-1}$. O 'Trifoliata' e o citrangeiro 'Troyer' mostraram efeito quadrático positivo e apresentaram os maiores valores para essas variáveis na dose $1,0 \mathrm{~g} \mathrm{~L}^{-1}$. Já a tangerineira 'Sunki' apresentou um comportamento linear crescente (Figura 1C). Para a área foliar por planta, o 'Trifoliata' e o citrumeleiro 'Swingle' mostraram um comportamento quadrático negativo, saturando a resposta na dose de $0,35 \mathrm{~g} \mathrm{~L}^{-1}$ e na dose máxima, respectivamente (Figura 1D). O citrangeiro 'Troyer' apresentou comportamento quadrático positivo, com os valores máximos obtidos na dose máxima, e a tangerineira 'Sunki' sofreu efeito linear crescente da aplicação de fertilizantes (Figura 1D).

O acúmulo de massa seca na raiz e na parte aérea (Figuras 1E-F) também sofreu interação significativa entre porta-enxertos e doses de solução nutritiva, uma vez que a tangerineira 'Sunki' e o citrumeleiro 'Swingle' apresentaram efeito quadrático negativo e positivo, respectivamente, para a massa seca da raiz, e os demais porta-enxertos apresentaram comportamento linear crescente (Figura 1E). Ao passo que o 'Trifoliata' e a 'Sunki' apresentaram comportamento linear crescente para a massa seca da parte aérea e o 'Troyer' teve resposta quadrática positiva, devido ao aumento da fertilização, enquanto o citrumeleiro 'Swingle' mostrou efeito quadrático negativo, saturando a resposta na dose de $0,5 \mathrm{~g} \mathrm{~L}^{-1}$ (Figura 1F). Apesar das interações significativas e das pequenas diferenças estatísticas, pode-se verificar que, com exceção da tangerineira 'Sunki', todos os portaenxertos tiveram aumento de massa seca com crescimento das doses de solução nutritiva.

A comparação geral dos resultados obtidos pela testemunha sem fertilizante, com os demais tratamentos, demonstra claramente a importância do fornecimento de nutrientes para a formação dos portaenxertos de citros. A ausência de suplementação mineral comprometeu o crescimento das plantas, que apresentaram desempenho bastante inferior ao daquelas adubadas com solução nutritiva, confirmando as observações de DECARLOS NETO et al. (2002) e SCIVITTARO et al. (2004).

O substrato Comercial 1 propiciou incrementos de $10 \%$ na altura final, cerca de $9 \%$ no diâmetro e mais de $20 \%$ no acúmulo de matéria seca em relação ao comercial 2 (Tabela 1). A aplicação de fertilizantes via água de irrigação influenciou positivamente o crescimento da parte aérea e das raízes dos porta-enxertos cítricos testados. 


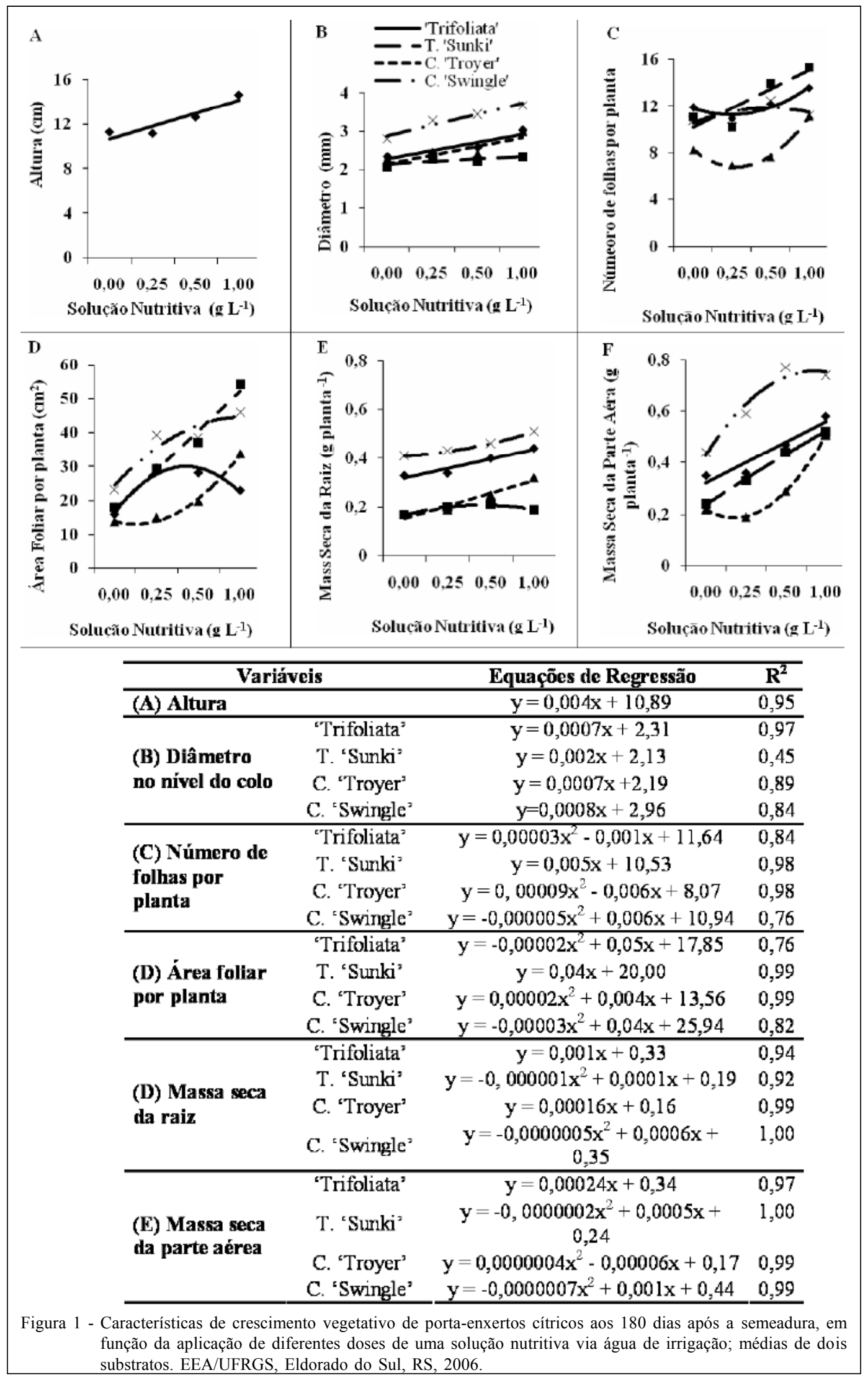

Ciência Rural, v.40, n.12, dez, 2010. 


\section{REFERÊNCIAS}

DECARLOS NETO, A. et al. Crescimento de porta-enxertos de citros em tubetes influenciados por doses de N. Revista Brasileira de Fruticultura, Jaboticabal, v.24, n.1, p.199203, abr. 2002. Disponível em: <http://www.scielo.br/ scielo.php? script=sci_arttext\&pid=S $0100-$ 29452002000100043>. Acesso em: 27 out. 2010. doi: 10.1590/S0100-29452002000100043.

SCHÄFER, G. et al. Desenvolvimento vegetativo de portaenxertos de citros cultivados em diversos substratos. In: ENCONTRO NACIONAL SOBRE SUBSTRATOS PARA PLANTAS, 2., 2000, Florianópolis. Anais... Florianópolis: UFSC, 2000. p.56-57.
SCHÄFER, G. Produção de porta-enxertos cítricos em recipientes e ambiente protegido no Rio Grande do Sul. 2004. 129f. Tese (Doutorado em Fitotecnia) - Programa de Pós-graduação em Fitotecnia, Faculdade de Agronomia, Universidade Federal do Rio Grande do Sul, Porto Alegre, RS.

SCIVITTARO, W.B. et al. Adubação nitrogenada na formação de porta-enxertos de limoeiro 'Cravo' em tubetes. Revista Brasileira de Fruticultura, Jaboticabal, v.26, n.1, p.131135, abr. 2004. Disponível em: <http://www.scielo.br/ scielo.php? script=sci_art text\&pid=S $0100-$ $29452004000100036 \& \operatorname{lng}=\mathrm{pt} \& \mathrm{nrm}=\mathrm{i}$ so\&tlng=pt $>$. Acesso em: 27 out. 2010. doi: 10.1590/S0100-29452004000100036. 